\title{
The 2015 ESC/ERS Guidelines for the diagnosis and treatment of pulmonary hypertension: a practical chronicle of progress
}

\author{
Edmund M.T. Lau' ${ }^{1}$ Yuichi Tamura $2,3,4,5$, Michael D. McGoon ${ }^{6}$ and \\ Olivier Sitbon ${ }^{3,4,5}$
}

\begin{abstract}
Affiliations: ${ }^{1}$ Department of Respiratory Medicine, Royal Prince Alfred Hospital, University of Sydney, Camperdown, Australia. ${ }^{2}$ Department of Cardiology, Keio University School of Medicine, Tokyo, Japan. ${ }^{3}$ Univ. Paris-Sud, Le Kremlin-Bicêtre, France. ${ }^{4}$ AP-HP, Service de Pneumologie, DHU Thorax Innovation, Hôpital Bicêtre, Le Kremlin-Bicêtre, France. ${ }^{5}$ INSERM UMR_S999, LabEx LERMIT, Centre Chirurgical Marie Lannelongue, Le Plessis Robinson, France. 'Division of Cardiovascular Disease (Emeritus), College of Medicine, Mayo Clinic, Rochester, MN, USA.
\end{abstract}

Correspondence: Edmund M.T. Lau, Department of Respiratory Medicine, Royal Prince Alfred Hospital, Missenden Road, University of Sydney, Camperdown 2050, Australia. E-mail: edmund.laudasydney.edu.au

0 @ERSpublications

For the busy clinician, what is new in the 2015 ESC/ERS guidelines on pulmonary hypertension? http://ow.ly/QwKUx

The first World Health Organization (WHO) Symposium on Pulmonary Hypertension was held in 1973 in response to the sudden increase in the number of patients with primary pulmonary hypertension (PPH) [1]. This epidemic was related to the intake of appetite-suppressing drugs and only 17 clinicians and scientists convened at the landmark first WHO meeting. Back then, PPH was a mysterious condition without any known therapy. Two decades later, in 1993, the first consensus guideline on PPH endorsed by a specialist society was published [2]. The chairman of the 1993 consensus document, Lewis Rubin (University of California, San Diego, CA, USA), recognised the limited knowledge and science in the field at the time, and remarked some years later that "our task was relatively easy...since the published literature was fairly limited. Accordingly, our guidelines were largely driven by expert opinion" [3]. Since then, we have witnessed dramatic leaps in our knowledge of both the basic and clinical science of pulmonary hypertension. Intravenous epoprostenol, the first of many targeted pulmonary arterial hypertension (PAH) therapies that are currently available, gained US Food and Drug Administration approval in 1995. The turn of the 21st century saw the emergence of efficacious oral therapies that have altered the care of patients with PAH.

Numerous guidelines on pulmonary hypertension have since been developed by specialist societies across both the European and American continents as the science of pulmonary hypertension has evolved [3-8]. With time, the rigour and methodology of guideline development in clinical medicine have also improved. Practice guidelines are intended to provide clinicians with recommendations based on systematic review of the available evidence, and an assessment of the benefits and harms of care options, with the intention of optimising patient outcomes [9]. Expert opinion remains a major part of all practice guidelines, particularly when high-quality evidence is lacking. The last European Society of Cardiology (ESC)/ European Respiratory Society (ERS) Guidelines for the Diagnosis and Treatment of Pulmonary Hypertension were published back in 2009 [5, 6]. Pulmonary hypertension is a rapidly moving field and many new developments have since occurred in a relatively short space of time. Thus, the new 2015

Received: July 202015 | Accepted after revision: July 252015

Conflict of interest: Disclosures can be found alongside the online version of this article at erj.ersjournals.com

Copyright @ERS 2015 
ESC/ERS guidelines [10] have been eagerly anticipated and will be welcomed by all professionals involved in the care of the pulmonary hypertension patient. In recognition that pulmonary hypertension can complicate a diverse range of medical conditions and is not the exclusive domain of any medical specialty, the 2015 ESC/ERS guidelines have been developed by an interdisciplinary panel of experts.

For the busy clinician, what is new in the 2015 ESC/ERS guidelines? The definitions and classification of pulmonary hypertension are now aligned with the recent recommendations of the fifth World Symposium on Pulmonary Hypertension [11, 12]. Haemodynamic criteria for the diagnosis of pulmonary hypertension are unaltered from previous guidelines, with the exception that a pulmonary vascular resistance $>3$ Wood units is now required to diagnose PAH. There remains no consensus definition for exercise pulmonary hypertension due to insufficient data, despite the growing interest and research in the role of exercise testing for the early detection of pulmonary vascular disease [13]. The clinical classification of pulmonary hypertension has been adapted from the fifth World Symposium but an expanded subclassfication for group $1^{\prime}$ pulmonary veno-occlusive disease (PVOD) is now proposed. Recently, biallelic mutations in the EIF2AK4 gene were discovered to be the major genetic cause of PVOD [14] and it is increasingly acknowledged that PVOD can complicate systemic sclerosis or be induced by toxins such as chemotherapy agents [15-17]. Accordingly, a subclassification for PVOD is suggested to reflect our new knowledge of these distinct aetiologies.

The diagnostic algorithm for pulmonary hypertension has undergone some cosmetic changes but the general principles remain similar. A greater emphasis has been devoted to genetic testing in the 2015 ESC/ERS guidelines. Both PAH and PVOD have strong genetic predispositions, and patients with sporadic or heritable disease should be advised regarding the availability of genetic testing and counselling, given the possibility that many will carry a disease-causing mutation. Specific recommendations are also provided on the approach on how to test for the different genes implicated in PAH and PVOD.

One aspect of the 2015 ESC/ERS guidelines that might be of immense interest for clinicians is the new treatment algorithm for PAH. The expansion of the therapeutic armamentarium in PAH and recent trials focussing on combination therapy have meant that treatment strategies are now much more complex [18-21]. Many different combinations of PAH drugs from different classes are now possible to target the three main pathomechanistic pathways implicated in disease development (prostacyclin, endothelin-1 and nitric oxide pathways) [22]. In addition, combination therapy can be given with an upfront approach or sequentially if treatment targets are not met.

The new treatment algorithm suggests that when considering initial or de novo therapy in PAH, patients should first undergo risk stratification into either the low/intermediate- or high-risk group. Although the low/intermediate- and high-risk groups correspond broadly to those in WHO functional class II-III and IV, respectively, it is acknowledged that some patients in WHO functional class III will be classified as high-risk when other prognostic parameters such as 6-min walk distance, brain natriuretic peptides, right ventricular function and haemodynamics are considered. For those stratified as high-risk, upfront combination therapy is advocated and should include i.v. epoprostenol, given the fact that i.v. epoprostenol remains the only drug to have demonstrated a survival benefit over 3 months in PAH. A recent open-label study [23] demonstrated that upfront triple combination therapy in very severe PAH was associated with impressive haemodynamic and functional responses that were sustained at long-term follow-up, providing proof of the concept of a more aggressive treatment approach in this population.

Perhaps the biggest change comes with the recommendation that low/intermediate-risk patients should also be offered upfront combination therapy. This recommendation comes from the recently published AMBITION study [24], demonstrating that upfront combination with ambrisentan and tadalafil was associated with a $50 \%$ reduction in the primary composite morbidity/mortality end-point, as compared with ambrisentan or tadalafil alone. Despite the compelling results of the AMBITION study, the new treatment algorithm has adopted a sensible approach and has recommended that initial monotherapy remains an equally acceptable alternative for low/intermediate-risk patients. At an individual-patient level, clinical experience indicates that there are many patients who achieve treatment targets on monotherapy and do well over the long term. Furthermore, what remains unknown is whether upfront combination therapy is superior to an optimised sequential combination therapy strategy. In other words, upfront combination therapy has never been properly tested against an aggressive sequential strategy where additional therapy is added if treatment targets are not met at early review following initiation of monotherapy.

In terms of sequential combination therapy, the broad principles recommended by the new guidelines are preserved from the previous guidelines. The aim is to set high treatment goals that will place patients into a low-risk category, essentially translating to good exercise capacity, the absence of clinical right heart failure and good right ventricular function. If treatment goals are not met, additional therapy should be 
introduced at early follow-up. However, with the many PAH drugs that are now available, are there any drug combinations that are considered ideal?

There remain no head-to-head randomised controlled trials (RCTs) that have evaluated the outcomes of different combination therapies in PAH. Furthermore, such trials are unlikely to be performed in the near future. However, sequential combination therapy trials have not yielded consistently positive results and the current guidelines have attempted to stratify the level of evidence according to the results obtained from these studies. Specific combinations of PAH drugs that have yielded positive primary end-points from RCTs have been given a higher level of recommendation accordingly.

Since the last guidelines, there have also been significant advances in pharmacological and interventional approaches to the management of chronic thromboembolic pulmonary hypertension (CTEPH). Pulmonary endarterectomy remains the treatment of choice for those with operable disease. For those with inoperable CTEPH or persistent/recurrent CTEPH following surgery, targeted therapy with the soluble guanylate stimulator riociguat is recommended, which has been demonstrated to improve haemodynamics and functional capacity [25]. Balloon pulmonary angioplasty is gaining momentum worldwide and experienced centres are now offering this percutaneous intervention alone or in combination with targeted therapy for inoperable disease. An updated treatment algorithm for CTEPH is proposed in the new guidelines that incorporates these new treatment options for inoperable disease.

Despite their wide promulgation, the effect of guidelines on changing physician behaviour can be variable [26]. As evidenced by a recent study on real-life physician adherence to guidelines, only $6 \%$ of patients with a diagnosis of PAH underwent all of the recommended tests that should be performed as part of the diagnostic workup [27]. Although guidelines are not intended to provide a "cookbook" that is universally applicable to all patients with complex disorders such as PAH, significant gaps exist between guidelines recommendations and clinical practice. Thus, it is equally important to identify barriers that prevent adoption of guidelines, and guidelines have been shown to be more effective in changing practice patterns when they are accompanied by active implementation strategies such as standing orders, reminder systems, clinical audit and feedback [28].

Finally, pulmonary hypertension is a global health issue but regional differences are present with regards to healthcare resources, healthcare priorities and access to high-cost medications. Thus, international guidelines are not necessarily applicable to all regions of the world. Such disparities are not confined to the developing countries; for example, subsidised combination therapy for PAH is still not available in Australia. In countries where medication access remains limited, the 2015 ESC/ERS guidelines should provide further support for clinicians and stakeholders to lobby for wider medication access that are in line with world's best practice.

\section{References}

1 Hatano S, Strasser T. Primary pulmonary hypertension: report on a WHO meeting. Geneva, World Health Organization, 1975.

2 Rubin LJ. Primary pulmonary hypertension. Chest 1993; 104: 236-250.

3 Rubin LJ. American College of Chest Physicians. Diagnosis and management of pulmonary arterial hypertension: ACCP evidence-based clinical practice guidelines. Chest 2004; 126: 7S-10S.

4 McLaughlin VV, Archer SL, Badesch DB, et al. ACCF/AHA 2009 expert consensus document on pulmonary hypertension: a report of the American College of Cardiology Foundation Task Force on Expert Consensus Documents and the American Heart Association developed in collaboration with the American College of Chest Physicians; American Thoracic Society, Inc.; and the Pulmonary Hypertension Association. J Am Coll Cardiol 2009; 53: 1573-1619.

5 Galie N, Hoeper MM, Humbert M, et al. Guidelines for the diagnosis and treatment of pulmonary hypertension: the task force for the diagnosis and treatment of pulmonary hypertension of the European Society of Cardiology (ESC) and the European Respiratory Society (ERS), endorsed by the International Society of Heart and Lung Transplantation (ISHLT). Eur Heart J 2009; 30: 2493-2537.

6 Task Force for Diagnosis and Treatment of Pulmonary Hypertension of European Society of Cardiology, European Respiratory Society, International Society of Heart and Lung Transplantation, et al. Guidelines for the diagnosis and treatment of pulmonary hypertension. Eur Respir J 2009; 34: 1219-1263.

7 Taichman DB, Ornelas J, Chung L, et al. Pharmacologic therapy for pulmonary arterial hypertension in adults: CHEST guideline and expert panel report. Chest 2014; 146: 449-475.

8 Mehta S, Helmersen D, Provencher S, et al. Diagnostic evaluation and management of chronic thromboembolic pulmonary hypertension: a clinical practice guideline. Can Respir J 2010; 17: 301-334.

9 Institute of Medicine. Consensus report: clinical practice guidelines we can trust. http://iom.nationalacademies.org/ Reports/2011/Clinical-Practice-Guidelines-We-Can-Trust.aspx Date last accessed: July 12, 2015. Date last updated: March 23, 2011.

10 Galiè N, Humbert M, Vachiery J-L, et al. 2015 ESC/ERS Guidelines for the diagnosis and treatment of pulmonary hypertension. Eur Respir J 2015; 46: 903-975.

11 Simonneau G, Gatzoulis MA, Adatia I, et al. Updated clinical classification of pulmonary hypertension. J Am Coll Cardiol 2013; 62: D34-D41. 
12 Hoeper MM, Bogaard HJ, Condliffe R, et al. Definitions and diagnosis of pulmonary hypertension. J Am Coll Cardiol 2013; 62: D42-D50.

13 Lau EM, Humbert M, Celermajer DS. Early detection of pulmonary arterial hypertension. Nature Rev Cardiol 2015; 12: 143-155.

14 Eyries M, Montani D, Girerd B, et al. EIF2AK4 mutations cause pulmonary veno-occlusive disease, a recessive form of pulmonary hypertension. Nature Genet 2014; 46: 65-69.

15 Gunther S, Jais X, Maitre S, et al. Computed tomography findings of pulmonary venoocclusive disease in scleroderma patients presenting with precapillary pulmonary hypertension. Arthritis Rheum 2012; 64: 2995-3005.

16 Ranchoux B, Gunther S, Quarck R, et al. Chemotherapy-induced pulmonary hypertension: role of alkylating agents. Am J Pathol 2015; 185: 356-371.

17 Perros F, Gunther S, Ranchoux B, et al. Mitomycin-induced pulmonary veno-occlusive disease: evidence from human disease and animal models. Circulation 2015 [In press DOI: 10.1161/CIRCULATIONAHA.115.014207].

18 Ghofrani HA, Galie N, Grimminger F, et al. Riociguat for the treatment of pulmonary arterial hypertension. N Engl J Med 2013; 369: 330-340.

19 Pulido T, Rubin LJ, Simonneau G. Macitentan and pulmonary arterial hypertension. N Engl J Med 2014; 370: 82-83.

20 McLaughlin V, Channick R, Chin KM, et al. Effect of selexipag on morbidity/mortality in pulmonary arterial hypertension: results of the GRIPHON study. J Am Coll Cardiol 2015; 65: Suppl., A380.

21 McLaughlin V, Channick R, Ghofrani HA, et al. Bosentan added to sildenafil therapy in patients with pulmonary arterial hypertension. Eur Respir J 2015; 46: 405-413.

22 Humbert M, Lau EM, Montani D, et al. Advances in therapeutic interventions for patients with pulmonary arterial hypertension. Circulation 2014; 130: 2189-2208.

23 Sitbon O, Jais X, Savale L, et al. Upfront triple combination therapy in pulmonary arterial hypertension: a pilot study. Eur Respir J 2014; 43: 1691-1697.

24 Galie N, Barbera JA, Frost A, et al. AMBITION: A randomised, multicentre study of first line ambrisentan and tadalafil combination therapy in subjects with pulmonary arterial hypertension (PAH). Eur Respir J 2014; 44: A2916.

25 Ghofrani HA, D'Armini AM, Grimminger F, et al. Riociguat for the treatment of chronic thromboembolic pulmonary hypertension. N Engl J Med 2013; 369: 319-329.

26 Lomas J, Anderson GM, Domnick-Pierre K, et al. Do practice guidelines guide practice? The effect of a consensus statement on the practice of physicians. N Engl J Med 1989; 321: 1306-1311.

27 McLaughlin VV, Langer A, Tan M, et al. Contemporary trends in the diagnosis and management of pulmonary arterial hypertension: an initiative to close the care gap. Chest 2013; 143: 324-332.

28 Bero LA, Grilli R, Grimshaw JM, et al. Closing the gap between research and practice: an overview of systematic reviews of interventions to promote the implementation of research findings. The Cochrane Effective Practice and Organization of Care Review Group. BMJ 1998; 317: 465-468. 